\title{
Moses technology in a stone simulator
}

Ahmed Ibrahim, MD, MSc ${ }^{1,2}$; Shadi Badaan, MD³; Mostafa M. Elhilali, MD, PhD, FRCSC ${ }^{1}$; Sero Andonian, MD, MSc, FRCSC, FACS ${ }^{1}$

${ }^{1}$ Department of Urology, Royal Victoria Hospital, McGill University Health Centre, Montreal. QC, Canada; ${ }^{2}$ Department of Urology, Alhussain University Hospital, Al-Azhar University, Cairo, Egypt; ${ }^{3}$ Department of Urology, Rambam Health Care Campus, Haifa, Israel

Acknowledgments: Moses D/F/L fibers were gratuitously provided by Lumenis for the study.

Cite as: Can Urol Assoc J 2017 Dec. 22; Epub ahead of print. http://dx.doi.org/10.5489/cuaj.4797

Published online December 22, 2017

***

\section{Abstract}

Introduction: The objective of this study was to compare fragmentation efficiency of the conventional regular mode of holmium laser to the Moses contact mode on a stone simulator. Methods: The Lumenis ${ }^{\circledR}$ Pulse ${ }^{\mathrm{TM}} \mathrm{P} 120 \mathrm{H}$ holmium laser system together with Moses D/F/L fibers were used to compare regular mode with Moses contact mode in a stone simulator model using flexible ureteroscopy with artificial stones. Efficiency of laser lithotripsy was measured by procedural time. Degree of stone retropulsion was also compared between regular and Moses modes using a Likert scale from zero (no retropulsion) to grade 3 (maximum retropulsion). Results: Using the stone simulator model, a significant reduction in stone retropulsion was noticed when comparing regular mode to the Moses contact mode (mean grade 2.5 vs. grade 1 ; $\mathrm{p}<0.01$ ). When compared with the regular mode, the Moses contact mode was associated with significantly shorter procedural time during fragmentation (13.9 vs. 9.1 minutes; $\mathrm{p} \leq 0.01$ ) and dusting (9.3 vs. 7.1 minutes; $p \leq 0.01$ ). In addition, when compared with the regular mode the laser pedal was pressed significantly less often with the Moses mode during fragmentation (86 vs. 43 times; $\mathrm{p}<0.01$ ) and dusting ( 50 vs. 26 times; $\mathrm{p}<0.01$ ). Moses contact mode was associated with significantly higher percentage of lasing vs. pausing when compared with the regular mode for both fragmentation $(0.8 \mathrm{~J} / 10 \mathrm{~Hz})$ and pulverization $(0.4 \mathrm{~J} / 50 \mathrm{~Hz})$ settings (both $\mathrm{p}<0.05)$.

Conclusions: Using the stone simulator setup, the Moses technology was associated with more efficient laser lithotripsy (shorter operative time) due to significantly reduced stone retropulsion. 


\section{Introduction}

Holmium:YAG laser is the gold standard energy source for intra-corporeal lithotripsy during endourologic procedures due to its ability to treat all types of the stones and its safety margin. ${ }^{1,2}$ However, retropulsion of stone fragments are frequently seen during laser lithotripsy especially when using high energies for ureteral stones. ${ }^{3,4,5,6}$ This necessitates the use of expensive and fragile flexible ureterosopes to look for the migrated renal stones. Sometimes, it is not possible to extract all renal stone fragments resulting in residual stone fragments. ${ }^{6,7}$ Therefore, development of a new laser technology minimizing stone retropulsion and thus improving effeciency of stone fragmentation and stone-free rates is needed.

Lumenis recently developed a new laser technology called "Moses technology" which has improved stone fragmentation capacity by increased energy transmission in water and reduced stone retropulsion in in vitro and animal studies. ${ }^{8}$ This new technology is based on modulation of the laser pulse to provide a much more efficient laser target interaction. The new Moses technology divides the current pulse into two adjacent peaks so that the first peak separates the water and the second peak travels through the bubble created by the first peak so that the second peak is delivered towards the stone, thus less energy is lost and the laser transmission is less dependent on fiber-stone distance (Moses effect) ${ }^{8}$ (Figure 1). Furthermore, the Moses technology has been optimized for "Contact" mode for lithotripsy at $1 \mathrm{~mm}$ and for "Distance" mode for lithotripsy at $2 \mathrm{~mm} .{ }^{8}$ However, there are no simulator studies evaluating the effectiveness of this new Moses technology in minimizing stone retropulsion during laser lithotripsy. Therefore, the objective of this study was to compare the fragmentation efficiency of the new Moses contact mode with the conventional Regular mode in a stone simulator model.

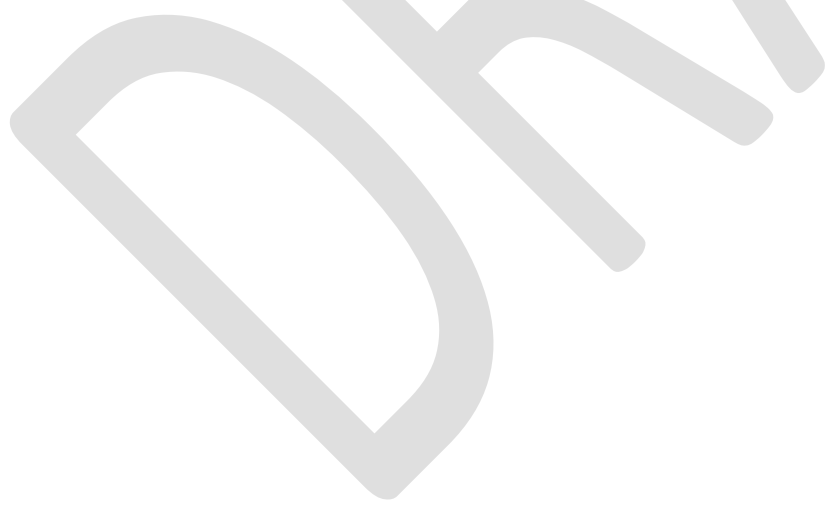




\section{Methods}

The stone simulator is a commercially available device (Medi-Skills models, Scotland, UK\# AST84/15) which mimics the urinary system including bladder, ureters and kidneys with different calyces. This model was previously validated and shown to be comparable to different endoscopic procedures. ${ }^{9}$ A pre-prepared round $5 \mathrm{~mm}$ artificial stone (UA 3000 and water 4:1 $\mathrm{w} / \mathrm{w}$ in weight) was placed in the lower pole of the kidney in the simulator. Using a ureteral access sheath (14 Fr, 35cm Cook, Bloomington, USA), a 8.5F flexible ureteroscope (Flex $X^{2}$, Storz, Tuttlingen, Germany) was inserted to the lower pole of the kidney and connected to a 3L normal saline irrigation using irrigation tubing and 3L pressure bag. Video endoscopy equipment was connected to the scope (Storz TELE PACK X video endoscopy system PN 20045001-EN) to record all sessions. The holmium laser generator (Lumenis Pulse ${ }^{T M} 120 H$ ) and the Moses 200 $\mathrm{D} / \mathrm{F} / \mathrm{L}$ fibers were used. In each session, 1 stone was treated using either Regular or "Contact" Moses mode at laser settings of either $(0.8 \mathrm{~J} / 10 \mathrm{~Hz})$ for stone fragmentation or $(0.4 \mathrm{~J} / 50 \mathrm{~Hz})$ for stone pulverization. Urologists had at least 14 years of experience with holmium:YAG laser lithotripsy. The stones were kept in contact with the laser fiber at all times. The degree of stone retropulsion for both Regular and Moses modes was graded subjectively by the urologist as follows: Grade 0: No retropulsion; Grade 1: Stone displaced and came back to the same location; Grade 2: Stone displaced and remained 1-2 cm away; Grade 3: Stone migrated elsewhere in the kidney or maximum retropulsion. All analyses were done as an average of 5 stones for each mode (Regular and Moses) for each laser setting.

The following parameters were measured and compared between the Regular and Moses modes: Procedure time as measured by the time from when the urologist started lasing till stone was pulverized to dust. Log files retrieved from the Lumenis ${ }^{\circledR}$ Pulse ${ }^{\mathrm{TM}} \mathrm{P} 120 \mathrm{H}$ laser generator were analyzed for lasing time, number of times the urologist pressed the laser pedal per procedure, percentage of time the laser was on vs. off per stone and the total energy required to fragment each stone.

Data was collected and tabulated using the commercially available SPSS software version 21 (SPSS Inc., Chicago, IL, USA). Descriptive statistics were presented in terms of percentages, frequencies, and means. Two tailed t-test was used for comparison of continuous variables. Two-tailed $\mathrm{p}$ values less than 0.05 were considered statistically significant.

\section{Results}

There was a significant reduction in the mean stone retropulsion grade from Regular to Moses contact mode (grade 2.5 vs. grade $1 ; \mathrm{p}<0.01$ ) (Figure 2). In addition, Moses technology resulted in significant reduction in the overall procedural duration for both fragmentation (13.9 vs. 9.1 min; $\mathrm{p}=0.01$ ) and dusting (9.3 vs. $7.1 \mathrm{~min} ; \mathrm{p}<0.01$ ) (Figure 3). However, there were no significant difference between Regular and Moses contact modes in total lasing time (5.8 vs. 5.3 
min, $\mathrm{p}>0.05$ ), total energies required to fragment (2.6 vs. $2.4 \mathrm{KJ}$ ) and pulverize the stones (5.3 vs. $5.2 \mathrm{KJ}$ ) (both $\mathrm{p}>0.05$ ) (Figure 3).

When compared with the Regular mode, the laser pedal was pressed significantly less often with the Moses contact mode during fragmentation (86 vs. 43 times; $\mathrm{p}<0.01$ ) and dusting (50 vs. 26 times; $\mathrm{p}<0.01$ ) (Figure 4). The percentage of lasing and pausing times were calculated for each procedure. Moses contact mode was associated with significantly higher percentage of lasing vs. pausing when compared with the Regular mode for both fragmentation $(0.8 \mathrm{~J} / 10 \mathrm{~Hz})$ and pulverization $(0.4 \mathrm{~J} / 50 \mathrm{~Hz}$ ) settings (both $\mathrm{p}<0.05$ ) (Figure 5).

\section{Discussion}

According to the latest guidelines, holmium:YAG laser lithotripsy is currently the gold standard for endoscopic lithotripsy due to its safety and efficacy. ${ }^{6,12,13}$ However, the efficiency of the holmium laser lithotripsy is partially limited by two main factors: stone retropulsion and energy transmission through water, which depends on fiber-stone distance. ${ }^{8}$ Since stone retropulsion leads to increased fiber-stone distance, these two factors are combined to reduce efficiency of laser lithotripsy using the conventional Regular mode. Based on "Moses effect" principle, the new Moses technology has been shown to improve stone fragmentation in in vitro and in vivo studies. ${ }^{8,14}$ Therefore, the aim of the present study was to compare the Regular mode to the new Moses contact mode in a stone simulator model. In the simulator model, the Moses contact mode was associated with a significant reduction in procedural time when compared with the Regular mode ( $\mathrm{p} \leq 0.01$ ) resulting in $35 \%$ and $23 \%$ reduction in the procedural time during fragmentation and pulverization settings, respectively (Figure 3 ). The improved efficiency of the Moses contact mode could be explained by the significantly less retropulsion during the Moses contact mode when compared with the Regular mode. It has been previously reported that one of the main factors in decreased efficiency during laser lithotripsy is renal stone migration resulting from stone retropulsion with increasing pulse energies. ${ }^{15}$ In the present study, the significant reduction in stone retropulsion explains the observed effects of the Moses technology including the significantly reduced number of times the pedal was pressed and the significantly higher percentage of time lasing vs. pausing was used (Figures 4 and 5). The reduced stone retropulsion enabled the urologist to lase for longer periods of time without the need for frequent pauses to reposition the tip of the fiber against the stone. This demonstrates one potential advantage of this new laser technology.

Regarding the pedal usage and the percent of lasing vs. pausing, our results revealed that when working with the Moses contact mode, the majority of the procedure time was dedicated to lasing during fragmentation (57\%) and pulverization (59\%) while a minor proportion was attributed to pauses during fragmentation (43\%) and pulverization (41\%). However, the opposite was found when using the conventional Regular mode (Figure 5). This explains the significant 
reduction in operative time associated with the Moses contact mode when compared with Regular mode.

This study is not without its limitations including the subjective assessment of stone retropulsion by the urologists. In addition, the urologists were not blinded when they graded the degree of retropulsion during the simulator study. Another limitation is that only the short pulse width of Regular mode was compared with the Moses contact mode. Nevertheless, this is the first simulator study to compare the Regular and Moses contact modes of holmium laser lithotripsy for their efficiency and stone retropulsion. In addition, the present study confirmed the in vitro findings of the significantly higher efficiency and significantly lower stone retropulsion associated with the Moses contact mode. A blinded randomized clinical trial is currently ongoing to confirm these results.

\section{Conclusions}

Using the stone simulator setup, Moses technology was associated with more efficient laser lithotripsy (shorter operative time) due to significantly reduced stone retropulsion. A randomized clinical trial is ongoing to confirm the improved efficiency of the Moses technology in a prospective blinded fashion. 


\section{References}

1. Zarrabi A and Gross AJ. The evolution of lasers in urology. The Adv Urol 2011; 3(2):819.

2. Marks AJ and Teichman JM. Lasers in clinical Urology: state of the art and new horizons. World J Urol 2007; 25(3): 227-33.

3. Gupta PK. Is the holmium. YAG laser the best intracorporeal lithotripter for the ureter? A 3-year retrospective study. J Endourol 2007; 21 (3):305-9.

4. Khoder WY1, Bader M, Sroka R, et al. Efficacy and safety of Ho:YAG laser lithotripsy for ureteroscopic removal of proximal and distal ureteral calculi. BMC Urol 2014: 14(62):1-7.

5. Ordon M, Andonian S, Blew B, et al. CUA Guideline: Management of ureteral calculi. Can Urol Assoc J 2015; 9(11-12):E837-51.

6. Türk C, Petř́k A, Sarica K, et al. EAU Guidelines on Interventional Treatment for Urolithiasis. Eur Urol 2016:69(3):475-482.

7. Chew BH, Brotherhood HL, Sur RL et al. Natural History, Complications and ReIntervention Rates of Asymptomatic Residual Stone Fragments after Ureteroscopy: a Report from the EDGE Research Consortium. J Urol 2016;195(4 Pt 1):982-6.

8. Elhilali MM, Badaan S, Ibrahim A, Andonian S. Use of the Moses Technology to Improve Holmium Laser Lithotripsy Outcomes: A Preclinical Study. J Endourol 2017; 31(6):598-604.

9. Brehmer M, Tolley D. Validation of a bench model for endoscopic surgery in the upper urinary tract. Eur Urol 2002; 42(2):175-9.

10. Graefen M. The Modified Clavien System: A Plea for a Standardized Reporting System for Surgical Complications. Eur Urol 2010; 57(3): 387-389.

11. Xu G1, Wen J1, Li Z, et al. A comparative study to analyze the efficacy and safety of flexible ureteroscopy combined with holmium laser lithotripsy for residual calculi after percutaneous nephrolithotripsy. J Clin Exp Med 2015;8(3):4501-7

12. Chen S, Zhou L, Wei T, et al. Comparison of Holmium: YAG Laser and Pneumatic Lithotripsy in the Treatment of Ureteral Stones: An Update Meta-Analysis. Urol Int 2017; 98(2):125-133

13. Li L, Pan Y, Weng Z, et al. A Prospective Randomized Trial Comparing Pneumatic Lithotripsy and Holmium Laser for Management of Middle and Distal Ureteral Calculi. $J$ Endourol 2015:29(8) 883-7.

14. Khoder WY1, Bader M, Sroka R, et al. Efficacy and safety of Ho:YAG laser lithotripsy for ureteroscopic removal of proximal and distal ureteral calculi. BMC Urol 2014: 14(62):1-7.

15. Blackmon RL, Irby PB, Fried NM. Comparison of holmium:YAG and thulium fiber laser lithotripsy: ablation thresholds, ablation rates, and retropulsion effects. J Biomed Opt 2011:16(7):071403. 
Figures and Tables

Fig. 1.

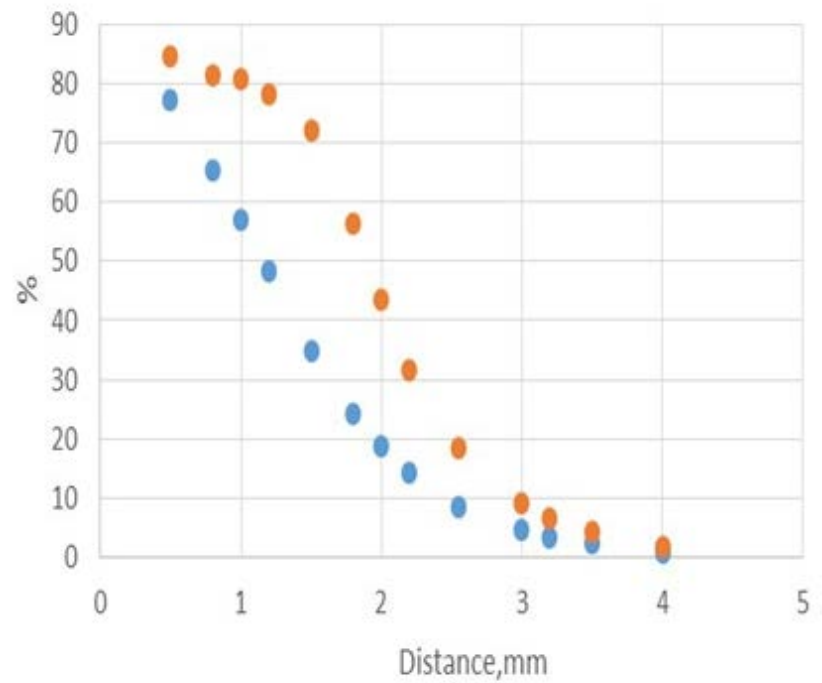

Fig. 2.

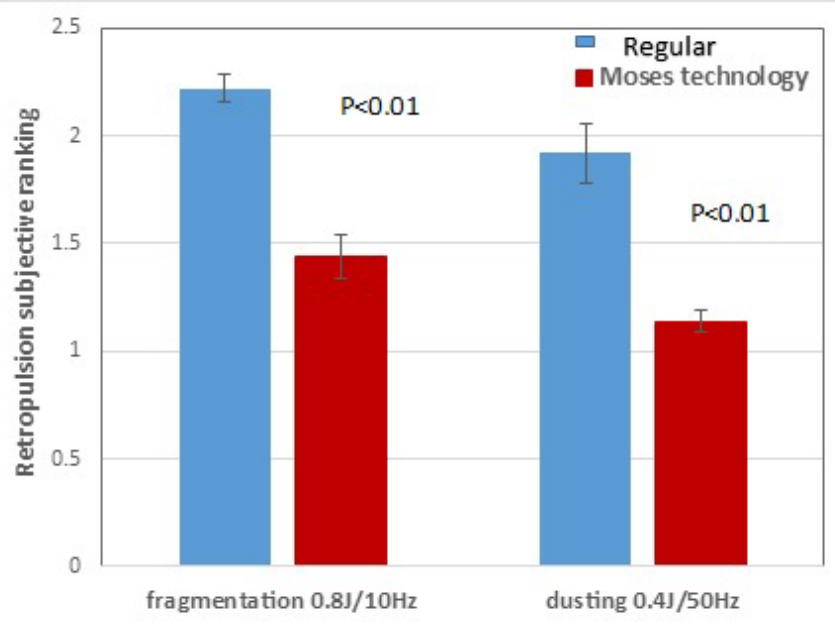


Fig. 3.

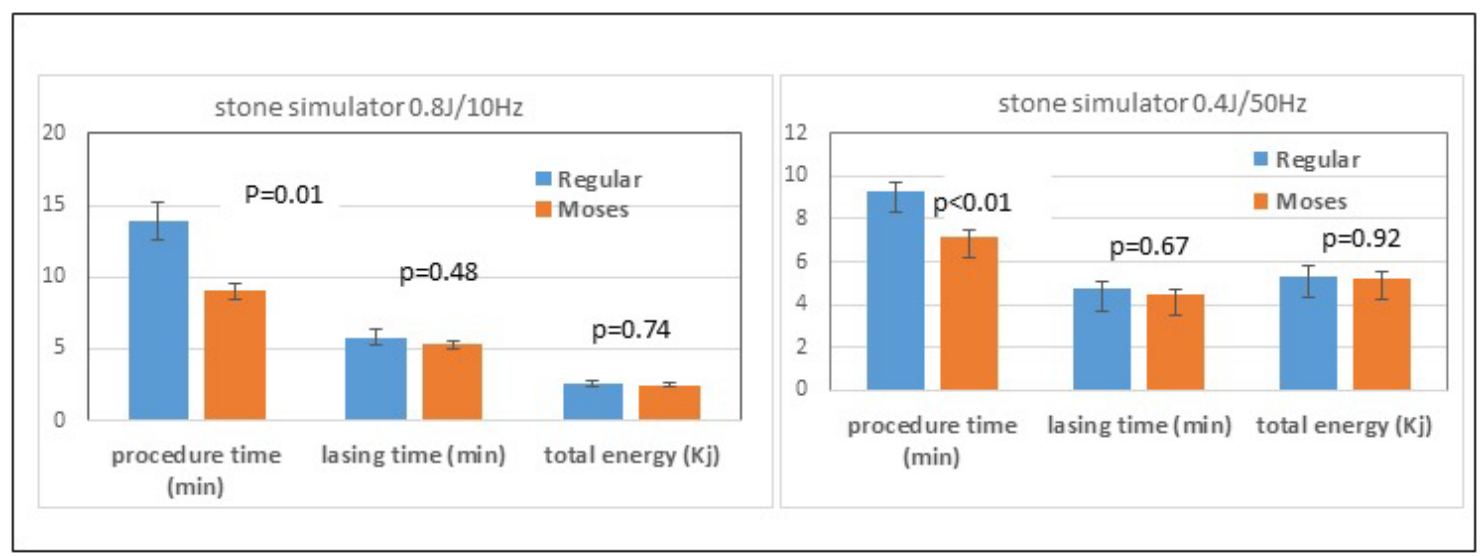

Fig. 4.

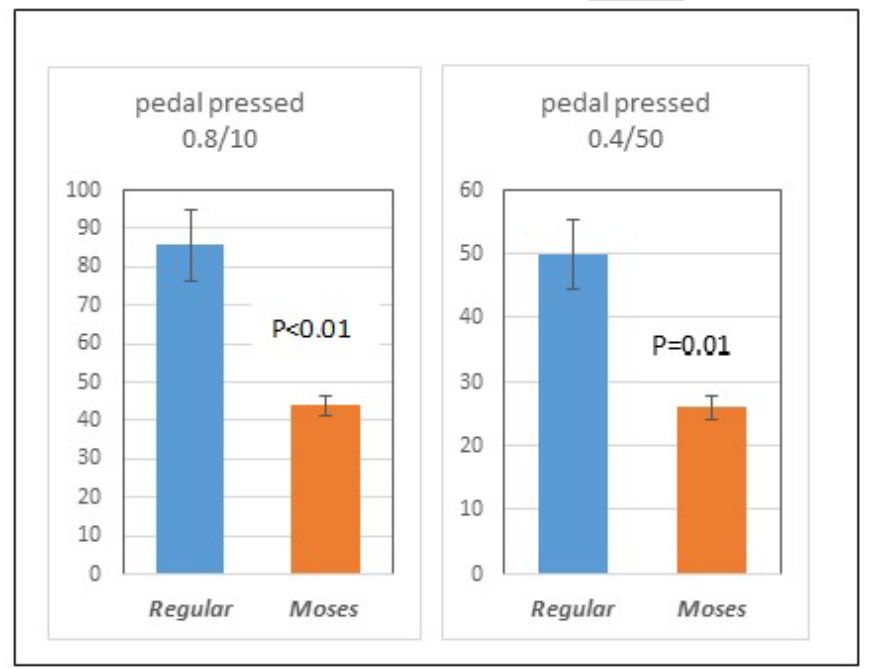


Fig. 5.

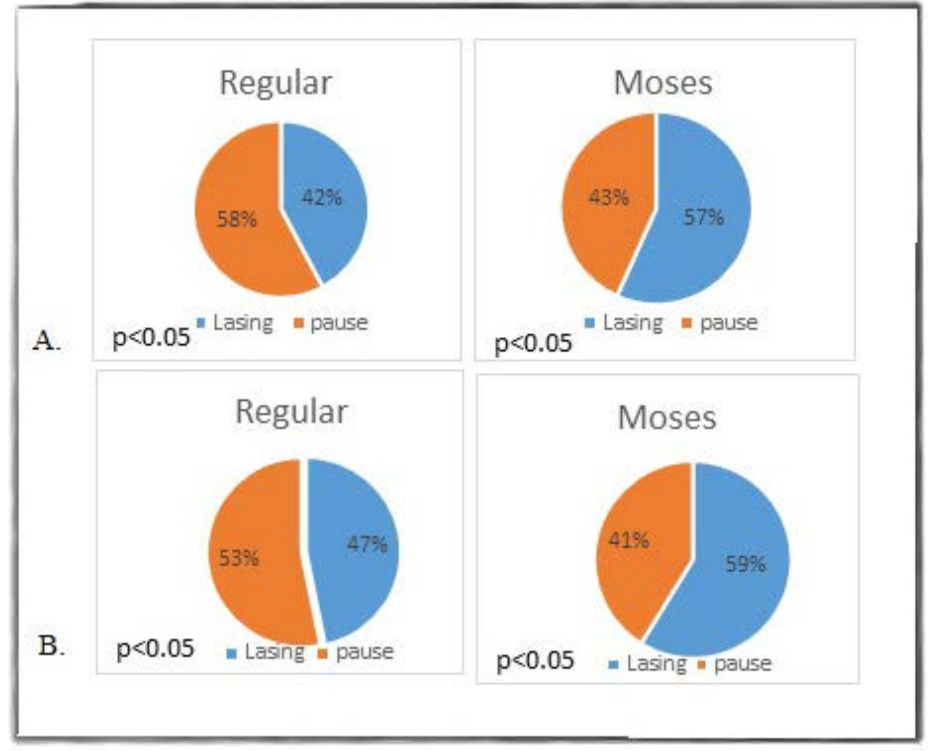

Fig. 6.

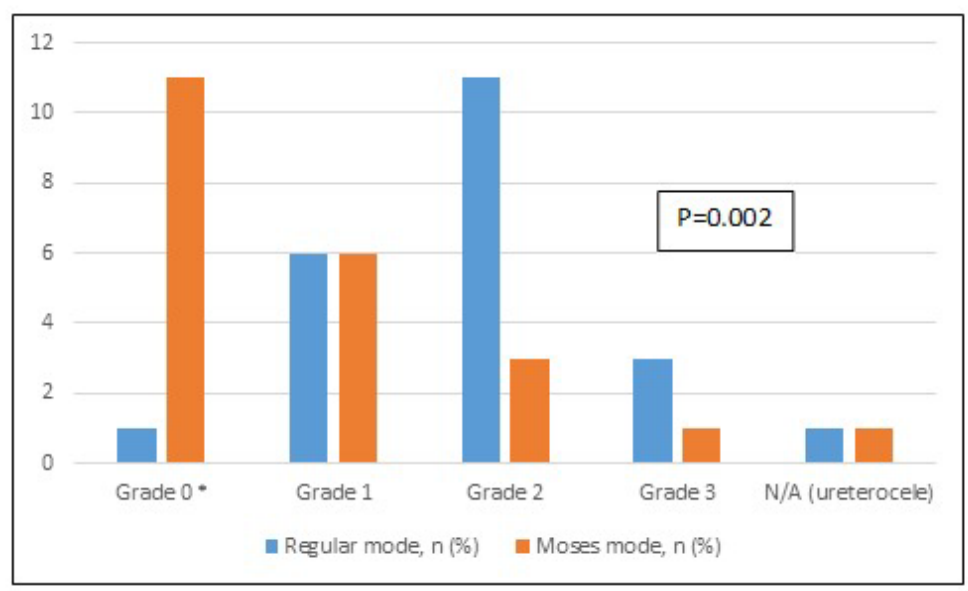

